\title{
B4 integrin subunit gene expression correlates with tumor size and nuclear grade in early breast cancer
}

\author{
Leslie K Diaz ${ }^{1}$, Massimo Cristofanilli ${ }^{2}$, Xiao Zhou ${ }^{1}$, Kristin L Welch ${ }^{1}$, Terry L Smith ${ }^{3}$, \\ Ying Yang ${ }^{3}$, Nour Sneige ${ }^{1}$, Aysegul A Sahin ${ }^{1}$ and Michael Z Gilcrease ${ }^{1}$ \\ ${ }^{1}$ Department of Pathology, University of Texas MD Anderson Cancer Center, Houston, TX, USA; ${ }^{2}$ Department \\ of Breast Medical Oncology, University of Texas MD Anderson Cancer Center, Houston, TX, USA and \\ ${ }^{3}$ Department of Biostatistics, University of Texas MD Anderson Cancer Center, Houston, TX, USA
}

\begin{abstract}
In vitro data support a role for the $\alpha 6 \beta 4$ integrin in tumor cell migration and invasion, particularly in breast carcinoma cells, but clinical data on this potentially important integrin are limited. The $\beta 4$ integrin subunit has been shown to cluster with genes characteristic of basal/myoepithelial cells in cDNA microarray analyses of breast cancer, and the subset of breast cancers with increased expression of genes characteristic of basal/ myoepithelial cells appears to be particularly aggressive. The purpose of this study was to determine whether a6/34 integrin expression correlates with aggressive clinicopathologic features of breast cancer and whether expression of this integrin has prognostic significance in early breast cancer. We evaluated tumor expression of the $\beta 4$ integrin subunit gene in a cohort of patients with early invasive breast carcinoma by in situ hybridization and correlated expression levels with multiple clinicopathologic characteristics. We also evaluated expression of laminin-5 protein, the principal ligand of $\alpha 6 \beta 4$, in this patient cohort. Although we observed a slight trend towards decreased disease-free survival for patients whose tumors had high $\beta 4$ gene expression and coexpression of laminin-5, this did not reach statistical significance $(P=0.11)$. However, we did observe a correlation between $\beta 4$ mRNA expression and both tumor size $(P=0.01)$ and tumor nuclear grade $(P<0.01)$. These results do not demonstrate prognostic significance for $\beta 4$ gene expression and/or laminin-5 protein expression in early breast cancer, but increased $\beta 4$ gene expression in larger tumors and in higher grade tumors does support a potential role for the $\alpha 6 \beta 4$ integrin in tumor progression.

Modern Pathology (2005) 18, 1165-1175. doi:10.1038/modpathol.3800411; published online 27 May 2005
\end{abstract}

Keywords: $\alpha 6 \beta 4$ integrin; in situ hybridization; laminin-5

A great deal of effort has gone into identifying markers for invasive breast carcinoma that can predict response to particular therapies. Hierarchical clustering analysis performed on cDNA microarray data has revealed a few distinct subgroups of invasive breast carcinomas that can be classified according to their patterns of gene expression. ${ }^{1}$ One such subgroup has been referred to as the basal/ myoepithelial group. A variety of genes expressed in basal cells and myoepithelial cells have been noted to cluster in a distinct subset of tumors comprising between 15 and $37 \%$ of invasive breast carcinomas. ${ }^{1-5}$ Clinically, this appears to be an aggressive

Correspondence: Dr MZ Gilcrease, MD, PhD, Department of Pathology, Box 85, MD Anderson Cancer Center, 1515 Holcombe Blvd., Houston, TX 77030, USA.

E-mail: mgilcrease@mdanderson.org

Received 5 January 2005; revised and accepted 27 January 2005; published online 27 May 2005 group of tumors. Two other groups whose gene expression patterns cluster as distinct subtypes include an estrogen receptor (ER)-positive group and a HER-2/neu-positive group. Both ER-positive and HER-2/neu-positive tumors currently have targeted therapies available, but the basal/myoepithelial group does not.

Among the gene products characteristic of the basal/myoepithelial group is the $\beta 4$ integrin subunit. ${ }^{1}$ Integrins are protein heterodimers that function as the major cell surface receptors for extracellular matrix proteins in multicellular animals. ${ }^{6,7}$ Each integrin heterodimer is composed of a single $\alpha$ and a single $\beta$ subunit. At present, $18 \alpha$ subunits and eight $\beta$ subunits have been identified, which combine to form 24 different integrins. ${ }^{6}$ The $\beta 4$ subunit is interesting because, in contrast to other integrin subunits that contain small cytoplasmic domains of around 50 amino acids, the large $\beta 4$ cytoplasmic domain contains approximately 1000 
amino acids (in most of its splice variants) and has signaling functions distinct from those of other integrins. ${ }^{8-14}$ The $\beta 4$ subunit is expressed only in combination with $\alpha 6$, so detection of the $\beta 4$ subunit indicates expression of the $\alpha 6 \beta 4$ integrin. ${ }^{6}$ This integrin mediates signal transduction through pathways known to be important in tumor cell motility and invasion. The $\alpha 6 \beta 4$ integrin or its downstream signaling effectors, therefore, could be important therapeutic targets for a subgroup of breast carcinomas lacking targeted therapies.

The $\alpha 6 \beta 4$ integrin functions as a receptor for laminin-5, a component of epithelial cell basement membranes. ${ }^{15-21}$ A previous retrospective study by Tagliabue et $a l^{22}$ using frozen tumor specimens from 80 patients with invasive breast carcinoma found an association between $\alpha 6 \beta 4$ integrin expression and poor clinical outcome. Tumors expressing both $\alpha 6 \beta 4$ and laminin were reported to have a particularly poor prognosis, but expression of the laminin-5 isoform was not specifically evaluated. ${ }^{22} \mathrm{~A}$ few primary breast carcinomas have been reported to coexpress $\alpha 6 \beta 4$ and laminin-5, ${ }^{23}$ but reported data are too limited to know the extent to which $\alpha 6 \beta 4$ and laminin-5 are coexpressed in invasive breast carcinoma. Coexpression of $\alpha 6 \beta 4$ and laminin-5 does not appear to be necessary for the function of $\alpha 6 \beta 4$, as some in vitro data suggest that $\alpha 6 \beta 4$ has important signaling functions that are ligand independent. ${ }^{16}$

Immunohistochemical staining for integrins can be successfully performed on frozen tissue sections, but we have had inconsistent staining results on formalin-fixed, paraffin-embedded tissues using multiple antibodies to the $\beta 4$ integrin subunit. We recently reported that an oligonucleotide probe for the $\beta 4$ integrin subunit is highly sensitive in detecting $\beta 4 \mathrm{mRNA}$ in formalin-fixed, paraffinembedded tissues. ${ }^{24}$ In this study, we evaluated tumor expression of $\beta 4$ mRNA and laminin-5 protein retrospectively in a cohort of patients with early invasive breast carcinoma who received no adjuvant chemotherapy or tamoxifen. Our purpose was to determine whether expression of $\alpha 6 \beta 4$ integrin or its principal ligand correlates with aggressive clinicopathologic features of breast cancer and whether their expression has prognostic significance in early breast cancer.

\section{Materials and methods}

This study was approved by the MD Anderson Institutional Review Board as Protocol LAB02-426. Tissue specimens from patients with lymph nodenegative invasive breast carcinoma who had surgery performed at MD Anderson Cancer Center (MDACC) between July of 1978 and October of 1995 were included in the study if the patients received no adjuvant tamoxifen or chemotherapy and if archival tissue blocks and clinical follow-up information were available. Clinical data were obtained from a database in the MDACC Department of Breast Medical Oncology. Formalin-fixed, paraffin-embedded tissue blocks were identified in the MDACC surgical pathology archives for 230 patients meeting study criteria.

To detect $\beta 4$ integrin subunit mRNA, we used a custom oligonucleotide probe (Research Genetics, Huntsville, AL, USA) that we previously reported to be highly sensitive and specific for the $\beta 4$ integrin subunit in archival paraffin tissue sections. ${ }^{24}$ The probe was designed with a $3^{\prime}$-hyperbiotinylated tail and the following sequence: $5^{\prime}$-GTAGTCCCTGGGCA GTGTGGTCGAG-TGTGAGTGTTCTGAG-3'. The GC content of the probe was $56 \%$. The probe was designed to recognize a 40-nucleotide sequence in the connecting segment of the $\beta 4$ cytoplasmic domain between two pairs of fibronectin type III repeats in a region that does not overlap with the insertions for variants $\beta 4 \mathrm{~B}$ and $\beta 4 \mathrm{C}^{8-14}$ (Figure 1). Paraffin sections were cut at $4-\mu \mathrm{m}$ intervals using RNase-free conditions. All instruments, glassware, and slides were washed overnight in $0.1 \%$ DEPC water, and histologic sections were cut using a $0.1 \%$ DEPC waterbath. The tissue sections were mounted on silane-treated ProbeOn slides (Fisher Scientific, Pittsburgh, PA, USA) and preheated at $65^{\circ}$ for 45 min before beginning the assay.

In situ hybridization was performed using the Microprobe System (Fischer Scientific, Pittsburgh, PA, USA) and the chromogen Fast Red (Biomeda Corp., Foster City, CA, USA) as previously described. ${ }^{25,26}$ Briefly, the glass slides were placed into the Microprobe holder and dewaxed with autodewaxer and dehydrated using Autoalcohol (Research Genetics). This was followed by digestion with Pepsin Reagent (Fisher Scientific) for $4 \mathrm{~min}$ at $100^{\circ} \mathrm{C}$. Sections were hybridized with the probe at $45^{\circ} \mathrm{C}$ for $1 \mathrm{~h}$, then washed 3 times at $45^{\circ} \mathrm{C}$ with $0.3 \mathrm{M}$ $\mathrm{NaCl}$ and $0.03 \mathrm{M}$ sodium citrate. Incubation with chromogen was performed at $45^{\circ} \mathrm{C}$ for $30 \mathrm{~min}$, followed by an additional incubation for $10 \mathrm{~min}$. Phosphatase Enhancer Reagent (Fisher Scientific) was applied to the samples for $1 \mathrm{~min}$ prior to both chromogen incubations. In situ hybridization with a polyd(T) 20-oligonucleotide probe (Research Genetics) was also performed on each case to verify the integrity of mRNA, and tumor samples with an

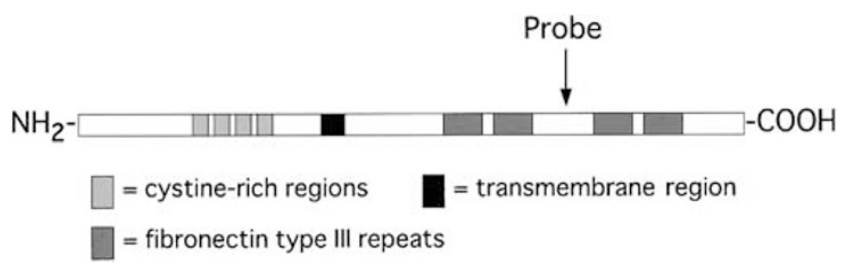

Figure 1 Schematic diagram of the $\beta 4$ integrin subunit. The oligonucleotide probe used for in situ hybridization recognizes a 40-nucleotide sequence in the connecting segment between the two pairs of fibronectin type III repeats in a region that does not overlap with the insertions for variants $\beta 4 \mathrm{~B}$ and $\beta 4 \mathrm{C}$. 
absence of polyd(T) staining were excluded from analysis.

Immunohistochemical staining for laminin-5 was performed using a monoclonal antibody to the laminin-5 $\gamma 2$ chain (clone D4B5, Chemicon) following Protease XXIV tissue pretreatment and a standard immunoperoxidase assay with diaminobenzidine (DAB) chromogen. Immunohistochemical staining for ER, progesterone receptor, and HER-2/ neu was performed with monoclonal antibodies 6F11 (Novocastra), 1A6 (Neomarkers), and e2-4001 (Neomarkers), respectively.

In situ hybridization for $\beta 4$ mRNA was scored as follows: negative, no cytoplasmic signal; low, weak cytoplasmic signal in at least $5 \%$ of cells; and high, strong cytoplasmic signal in at least $5 \%$ of cells. Immunohistochemical staining for laminin-5 was regarded as positive if at least $5 \%$ of cells had cytoplasmic staining or if staining was observed immediately surrounding invasive tumor cells (peritumoral staining). Peritumoral staining was scored as follows: negative, less than 5\% staining; low, greater than or equal to $5 \%$ but less than $20 \%$ staining; and high, greater than or equal to $20 \%$ staining. Staining for HER-2/neu was interpreted as positive for overexpression if at least $10 \%$ of tumor cells had complete membranous staining, and tumors with at least $10 \%$ nuclear staining were interpreted as positive for ER and progesterone receptor.

The Cochran-Armitage trend test was used to test for trends in binomial proportions across levels of a single factor or covariate. The Kruskal-Wallis rank sum test was used to compare groups of independent continuous variables. Disease-free survival (DFS) was defined as the interval from the date of surgery to the date of disease recurrence or death from breast cancer or to the last follow-up date. Disease-related survival (DRS) was defined as the interval from the date of surgery to the date of death from breast cancer or to the last follow-up date. Patients who died from causes other than breast cancer were censored when DRS was considered. Survival was estimated by using the Kaplan-Meier product limit method. The two-sided log-rank test was used to test the association between particular factors and survival. Statistical analyses were carried out using SAS 8.02 (SAS, Cary, NC, USA) and S-plus version 6 (Insightful Corp., Seattle, WA, USA).

\section{Results}

The median patient age for the 230 patients included in the study was 58 years (range: $28-83$ years). A total of $82 \%$ of patients were white, $8 \%$ were Hispanic, $7 \%$ were black, and $3 \%$ were Asian. In all, $81 \%$ were postmenopausal. The surgical procedure for $25 \%$ of patients was lumpectomy with axillary dissection, and $75 \%$ had a modified radical mastectomy. In all, $41 \%$ of patients received adjuvant radiation therapy, none received adjuvant tamoxifen, and none received chemotherapy. There were 139 T1, 88 T2, and 3 T3 tumors. The median tumor size was $2.0 \mathrm{~cm}$ (range: $0.6-7.0 \mathrm{~cm}$ ). Histologic subtypes included 91\% invasive ductal carcinomas, $6 \%$ invasive lobular carcinomas, and $3 \%$ other types. A total of $71 \%$ of tumors were ER positive, and $32 \%$ had HER-2/neu overexpression. The median clinical follow-up was 15 years.

During the 15-year follow-up period, there was disease recurrence in 63 patients. A total of 90 patients died, and 39 deaths were attributed to breast cancer. The estimated DFS (survival without tumor recurrence) for the entire group at 5 and 10 years was 80 and $74 \%$, respectively. The estimated DRS (noncancer-related deaths censored) at 5 and 10 years was 94 and $86 \%$, respectively. Standard pathologic features associated with DFS were tumor size $(P=0.04)$ and the presence of lymphovascular invasion $(P=0.03$, Table 1$)$. The only standard pathologic feature found to be associated with DRS was tumor size $(P=0.04$, Table 2$)$.

A total of 200 tumors were technically satisfactory for evaluation of $\beta 4$ mRNA expression by in situ hybridization. Two of these had an absence of polydT staining and were excluded from the analysis. For the remaining 198 cases, a high level of the $\beta 4$ integrin subunit mRNA was observed in 50 cases $(25 \%)$ (Figure 2). No association was found between $\beta 4$ mRNA expression and patient age, hormone receptor positivity, HER-2/neu overexpression, or lymphovascular invasion. There was a strong correlation between high $\beta 4$ mRNA expression and tumor nuclear grade $(P<0.01$, Table 3$)$, and high levels of $\beta 4$ mRNA were also associated with larger tumor size ( $P=0.01$, Table 3$)$. In all, 5 - and $10-$ year DFS for tumors with negative $\beta 4$ expression was 84 and $73 \%$, respectively, compared to 79 and $77 \%$ for tumors with high $\beta 4$ mRNA expression (Table 1). 5- and 10-year DRS for tumors with negative $\beta 4$ expression was 96 and $89 \%$, respectively, compared to 94 and $85 \%$ for tumors with high $\beta 4$ expression (Table 2). None of these survival differences was statistically significant (Figure 3a, b).

A total of 212 tumors were technically satisfactory for evaluation of laminin-5 immunohistochemical staining. Laminin-5 protein expression was observed in a linear staining pattern surrounding all normal ducts and lobules (Figure 4a) and around all ducts involved by ductal carcinoma in situ (DCIS) (Figure 4b). Extracellular deposition of laminin-5 immediately adjacent to invasive tumor cells was observed in 53 cases $(24.5 \%$ ) (Figure 4c, d). Laminin-5 was identified within the cytoplasm of invasive tumor cells in only 12 cases $(5.7 \%$ ) (Figure 4e). Only one case with cytoplasmic staining lacked extracellular deposition of laminin-5. A strong negative association was observed between peritumoral laminin-5 deposition and ER positivity 
Table 1 Disease-free survival (DFS) by clinicopathologic characteristics

\begin{tabular}{|c|c|c|c|c|c|}
\hline & $\begin{array}{c}\text { Total } \\
230\end{array}$ & $\begin{array}{c}\text { Events } \\
63\end{array}$ & $\begin{array}{c}5 \text {-year } \\
D F S \\
0.80\end{array}$ & $\begin{array}{c}\text { 10-year } \\
\text { DFS } \\
0.74\end{array}$ & P-value \\
\hline Patient age (years) & & & & & 0.86 \\
\hline$<50$ & 54 & 15 & 0.81 & 0.75 & \\
\hline$\geq 50$ & 176 & 48 & 0.79 & 0.73 & \\
\hline Tumor size $(\mathrm{cm})$ & & & & & 0.04 \\
\hline$\leq 2$ & 139 & 32 & 0.84 & 0.78 & \\
\hline$>2$ & 91 & 31 & 0.74 & 0.68 & \\
\hline Nuclear grade & & & & & 0.14 \\
\hline Low & 31 & 12 & 0.71 & 0.64 & \\
\hline Intermediate & 139 & 40 & 0.81 & 0.72 & \\
\hline High & 60 & 11 & 0.83 & 0.83 & \\
\hline $\begin{array}{l}\text { Lymphovascular } \\
\text { invasion }\end{array}$ & & & & & 0.03 \\
\hline Absent & 202 & 51 & 0.82 & 0.76 & \\
\hline Present & 28 & 12 & 0.64 & 0.56 & \\
\hline Estrogen receptor & & & & & 0.09 \\
\hline Negative & 66 & 13 & 0.82 & 0.82 & \\
\hline Positive & 159 & 50 & 0.79 & 0.70 & \\
\hline $\begin{array}{l}\text { Progesterone } \\
\text { receptor }\end{array}$ & & & & & 0.66 \\
\hline Negative & 149 & 41 & 0.79 & 0.74 & \\
\hline Positive & 75 & 22 & 0.79 & 0.71 & \\
\hline HER-2/neu & & & & & 0.26 \\
\hline Negative & 159 & 39 & 0.80 & 0.75 & \\
\hline Positive & 69 & 23 & 0.78 & 0.73 & \\
\hline$\beta 4$ integrin & & & & & 0.72 \\
\hline Negative & 57 & 18 & 0.84 & 0.73 & \\
\hline Low & 91 & 29 & 0.76 & 0.70 & \\
\hline High & 50 & 12 & 0.79 & 0.77 & \\
\hline Laminin-5 & & & & & 0.17 \\
\hline Negative & 160 & 45 & 0.80 & 0.74 & \\
\hline Low & 34 & 13 & 0.71 & 0.60 & \\
\hline High & 19 & 3 & 0.89 & 0.84 & \\
\hline
\end{tabular}

${ }^{*}$ Log-rank test.

$(P=0.005$, Table 3$)$. A negative association was also observed between peritumoral laminin-5 deposition and HER-2/neu overexpression $(P=0.02$, Table 3$)$. No association was found between peritumoral laminin-5 staining and patient age, tumor size, nuclear grade, progesterone receptor positivity, or lymphovascular invasion. No statistically significant differences in 5- and 10-year disease-specific (Table 1) or disease-related (Table 2) survival were observed for patients whose tumors had laminin-5 protein expression compared to patients whose tumors were negative for laminin-5 (Figure 3c, d).

A total of 194 tumors were technically satisfactory for evaluation of both $\beta 4$ mRNA expression by in situ hybridization and laminin-5 expression by immunohistochemical staining. Most tumors with upregulation of $\beta 4$ gene expression lacked detectable amounts of peritumoral laminin-5 deposition.
Table 2 Disease-related survival (DRS) by clinicopathologic characteristics

\begin{tabular}{|c|c|c|c|c|c|}
\hline & $\begin{array}{l}\text { Total } \\
230\end{array}$ & $\begin{array}{c}\text { Events } \\
39\end{array}$ & $\begin{array}{c}\text { 5-year } \\
\text { DRS } \\
0.94\end{array}$ & $\begin{array}{c}10 \text {-year } \\
\text { DRS } \\
0.86\end{array}$ & P-value* \\
\hline Patient age (years) & & & & & 0.25 \\
\hline$<50$ & 54 & 7 & 0.94 & 0.89 & \\
\hline$\geq 50$ & 176 & 32 & 0.94 & 0.86 & \\
\hline Tumor size $(\mathrm{cm})$ & & & & & 0.01 \\
\hline$\leq 2$ & 139 & 16 & 0.98 & 0.89 & \\
\hline$>2$ & 91 & 23 & 0.88 & 0.83 & \\
\hline Nuclear grade & & & & & 0.74 \\
\hline Low & 31 & 7 & 0.93 & 0.80 & \\
\hline Intermediate & 139 & 23 & 0.95 & 0.88 & \\
\hline High & 60 & 9 & 0.93 & 0.86 & \\
\hline $\begin{array}{l}\text { Lymphovascular } \\
\text { invasion }\end{array}$ & & & & & 0.50 \\
\hline Absent & 202 & 33 & 0.95 & 0.87 & \\
\hline Present & 28 & 6 & 0.86 & 0.79 & \\
\hline Estrogen receptor & & & & & 0.86 \\
\hline Negative & 66 & 12 & 0.91 & 0.84 & \\
\hline Positive & 159 & 27 & 0.95 & 0.87 & \\
\hline $\begin{array}{l}\text { Progesterone } \\
\text { receptor }\end{array}$ & & & & & 0.61 \\
\hline Negative & 149 & 28 & 0.93 & 0.86 & \\
\hline Positive & 75 & 11 & 0.96 & 0.86 & \\
\hline HER-2/neu & & & & & 0.24 \\
\hline Negative & 159 & 23 & 0.95 & 0.88 & \\
\hline Positive & 69 & 15 & 0.93 & 0.85 & \\
\hline$\beta 4$ integrin & & & & & 0.88 \\
\hline Negative & 57 & 10 & 0.96 & 0.89 & \\
\hline Low & 91 & 18 & 0.92 & 0.83 & \\
\hline High & 50 & 9 & 0.94 & 0.85 & \\
\hline Laminin-5 & & & & & 0.44 \\
\hline Negative & 160 & 27 & 0.94 & 0.85 & \\
\hline Low & 34 & 8 & 0.97 & 0.86 & \\
\hline High & 19 & 2 & 0.89 & 0.89 & \\
\hline
\end{tabular}

${ }^{*}$ Log-rank test.

No correlation was observed between $\beta 4$ gene expression and peritumoral laminin-5 deposition (Table 4). As shown in Figure 5a, no recurrences were observed for patients whose tumors were negative for $\beta 4$ gene expression but had high peritumoral laminin-5 deposition, but the number of patients in this group ${ }^{6}$ was too small for this finding to have statistical significance. There was a slight trend towards decreased disease-free survival for patients whose tumors had high $\beta 4$ gene expression and either low or high peritumoral laminin-5 deposition (Figure 5b), but the number of patients and events in this group (10 patients and five recurrences) were relatively few, and this result is not statistically significant $(P=0.11)$. There were insufficient disease-related deaths to evaluate DRS for subsets of patients whose tumors had particular combinations of $\beta 4$ and laminin-5 positivity. 

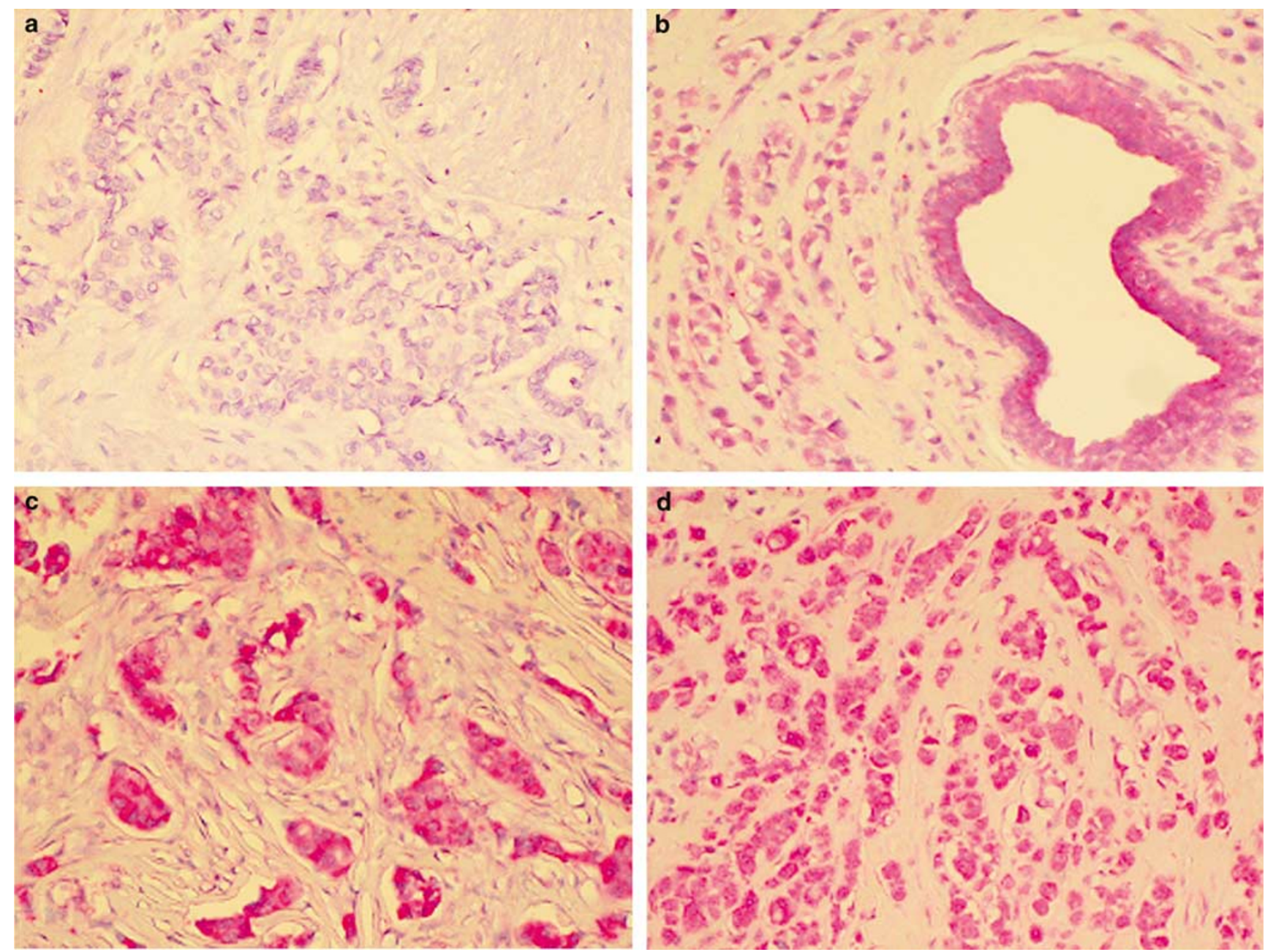

Figure 2 In situ hybridization for $\beta 4$ integrin subunit mRNA in representative cases of invasive carcinoma of the breast (Fast Red chromogen): (a) negative for $\beta 4$ expression (score 0, magnification $\times 200$ ); (b) weak $\beta 4$ expression (score $1+$, magnification $\times 200$ ); $(\mathbf{c}, \mathbf{d})$ strong $\beta 4$ expression (score $2+$, magnification $\times 200$ ). Note $\beta 4$ expression also in benign duct epithelium (right side of b).

\section{Discussion}

By linking information from the cell's environment to intracellular molecules, integrins are able to regulate processes as diverse as ion channel trafficking, intracellular protein kinase activity, and the organization of the intracellular actin cytoskeleton. ${ }^{6,27}$ Integrin signaling pathways also converge with those mediated by growth factor receptors, providing a mechanism whereby a particular extracellular environment can modulate the growth regulatory properties of cells. ${ }^{28,29}$ Consequently, integrin signaling plays an important role in cell cycle regulation, cell survival, differentiation, and motility. ${ }^{6}$ Alterations in integrin signaling are also important in various pathologic conditions. The $\alpha 6 \beta 4$ integrin, in particular, appears to be important in the progression of some types of malignancy, including invasive breast carcinoma. ${ }^{15-21,28,30,31}$

In breast carcinoma cell lines, ligation of the $\alpha 6 \beta 4$ integrin activates the PI3K-Akt pathway, thereby promoting tumor cell survival. ${ }^{16}$ The mTOR path- way downstream of $\alpha 6 \beta 4$ leads to increased VEGF production, which not only stimulates angiogenesis but also promotes tumor cell survival through an autocrine loop mechanism. ${ }^{20}$ Activation of PI3K by $\alpha 6 \beta 4$ also leads to increased tumor cell invasiveness. ${ }^{15,16,19,28,31}$ Tumor cell invasion involves the formation of actin-containing motility structures such as lamellipodia and filopodia, and $\alpha 6 \beta 4$ has been shown to localize to these structures in invasive tumor cells. ${ }^{17,18}$ Furthermore, ligation of $\alpha 6 \beta 4$ activates the Ras-MAP kinase pathway, ${ }^{32}$ and signaling through this pathway may stimulate cell motility through activation of myosin light-chain kinase and phosphorylation of nonmuscle myosin II light chain, the catalytic component of nonmuscle myosin II. ${ }^{32,33}$

Invasive breast carcinomas that overexpress $\alpha 6 \beta 4$ may acquire a myoepithelial-like phenotype. Myoepithelial cells are present in the ducts of normal breast tissue, where they are in contact with the basement membrane surrounding the ducts. ${ }^{34}$ 
Table 3 Correlation between $\beta 4$ integrin or laminin-5 positivity and clinicopathologic characteristics

\begin{tabular}{|c|c|c|c|c|c|c|}
\hline & \multicolumn{3}{|c|}{$\beta 4$ Integrin } & \multicolumn{3}{|c|}{ Laminin-5 } \\
\hline & Negative & Low & High & Negative & Low & High \\
\hline Total cases & 57 & 91 & 50 & 160 & 34 & 19 \\
\hline \multicolumn{7}{|c|}{ Patient age (years) } \\
\hline Median & 60 & 58 & 59 & 59 & 57 & 57 \\
\hline Range & $32-81$ & $28-83$ & $32-82$ & $30-82$ & $29-81$ & $28-76$ \\
\hline$P$-value & & $0.73^{\mathrm{a}}$ & & & $0.46^{\mathrm{a}}$ & \\
\hline \multicolumn{7}{|c|}{ Tumor size $(\mathrm{cm})$} \\
\hline $\begin{array}{l}\text { Mean } \pm \text { s.d. } \\
P \text {-value }\end{array}$ & $1.9 \pm 1.0$ & $\begin{array}{c}2.2 \pm 1.1 \\
0.01^{\mathrm{a}}\end{array}$ & $2.4 \pm 0.9$ & $2.2 \pm 1.0$ & $\begin{array}{c}2.2 \pm 1.2 \\
0.68^{\mathrm{a}}\end{array}$ & $2.0 \pm 1.0$ \\
\hline \multicolumn{7}{|l|}{ Nuclear grade } \\
\hline 1 & $14(25 \%)$ & $12(13 \%)$ & $2(4 \%)$ & $27(17 \%)$ & $2(6 \%)$ & $2(11 \%)$ \\
\hline $2-3$ & $43(75 \%)$ & $79(87 \%)$ & $48(96 \%)$ & $133(83 \%)$ & $32(94 \%)$ & $17(89 \%)$ \\
\hline$P$-value & & $<0.01^{\mathrm{b}}$ & & & $0.17^{\mathrm{b}}$ & \\
\hline \multicolumn{7}{|c|}{ Estrogen receptor } \\
\hline Negative & $18(32 \%)$ & $26(30 \%)$ & $12(24 \%)$ & $40(25 \%)$ & $10(29 \%)$ & $11(61 \%)$ \\
\hline Positive & $38(68 \%)$ & $62(70 \%)$ & $38(76 \%)$ & $118(75 \%)$ & $24(71 \%)$ & $7(39 \%)$ \\
\hline$P$-value & & $0.36^{\mathrm{b}}$ & & & $0.005^{\mathrm{b}}$ & \\
\hline \multicolumn{7}{|c|}{ Progesterone receptor } \\
\hline Negative & $35(62 \%)$ & $56(64 \%)$ & $36(72 \%)$ & $101(64 \%)$ & $23(68 \%)$ & $14(78 \%)$ \\
\hline Positive & $21(38 \%)$ & $32(36 \%)$ & $14(28 \%)$ & $57(36 \%)$ & $11(32 \%)$ & $4(22 \%)$ \\
\hline$P$-value & & $0.31^{\mathrm{b}}$ & & & $0.24^{\mathrm{b}}$ & \\
\hline \multicolumn{7}{|l|}{ HER-2/neu } \\
\hline Negative & $43(75 \%)$ & $58(64 \%)$ & $34(68 \%)$ & $103(64 \%)$ & $25(73 \%)$ & $17(89 \%)$ \\
\hline Positive & $14(25 \%)$ & $33(36 \%)$ & $16(32 \%)$ & $57(36 \%)$ & $9(27 \%)$ & $2(11 \%)$ \\
\hline$P$-value & & $0.45^{\mathrm{b}}$ & & & $0.02^{\mathrm{b}}$ & \\
\hline \multicolumn{7}{|c|}{ Lymphovascular invasion } \\
\hline Negative & $50(89 \%)$ & $69(79 \%)$ & $47(94 \%)$ & $134(85 \%)$ & $31(91 \%)$ & $17(95 \%)$ \\
\hline Positive & $6(11 \%)$ & $19(21 \%)$ & $3(6 \%)$ & $24(15 \%)$ & $3(9 \%)$ & $1(5 \%)$ \\
\hline$P$-value & & $0.58^{\mathrm{b}}$ & & & $0.15^{\mathrm{b}}$ & \\
\hline
\end{tabular}

${ }^{\mathrm{a}}$ Kruskal-Wallis rank sum test.

${ }^{\mathrm{b}}$ Cochran-Armitage trend test.

Myoepithelial cells are known to be proliferative and move through the adjacent stroma in some physiologic conditions. ${ }^{35}$ Tumors that overexpress $\alpha 6 \beta 4$ may similarly have an increased capacity for stromal invasion. This would be consistent with in vitro data showing increased invasiveness of breast carcinoma cell lines following transfection of $\alpha 6 \beta 4$ negative breast carcinoma cells with full-length $\beta 4 .{ }^{16}$

In cDNA microarray studies of invasive breast carcinoma, the basal/myoepithelial group of tumors is defined as those tumors expressing increased basal/myoepithelial markers compared to a reference set of nonmyoepithelial cell lines. ${ }^{1}$ In hierarchical clustering analysis, tumors overexpressing the $\beta 4$ integrin subunit and those with increased laminin-5 expression have been reported to cluster together. ${ }^{1}$ Some invasive tumors have a high DCIS component, which is a noninvasive malignant component still confined to ducts surrounded by benign myoepithelial cells. ${ }^{36,37}$ Tumors that cluster with the basal/myoepithelial group in hierarchical clustering analysis might include tumors with a high DCIS component (tumors that contain many associated benign myoepithelial cells). Such tumors would be expected to show a high correlation between expression of laminin-5 and other basal/ myoepithelial markers because normal myoepithelial cells produce laminin-5. ${ }^{38}$ Histologic evaluation of gene expression is necessary to determine whether particular cellular components of a tumor coexpress certain gene products. In our study, only $20 \%$ of the invasive tumors with high $\alpha 6 \beta 4$ expression had detectable amounts of laminin-5 by immunohistochemistry.

Both subunits of the $\alpha 6 \beta 4$ integrin have multiple known splice variants. No clear functional differences between the two $\alpha 6$ cytoplasmic variants have yet been identified when the $\alpha 6$ subunits are in association with $\beta 4 .{ }^{39-42}$ There are five known cytoplasmic splice variants of the $\beta 4$ subunit. $^{8-11,14}$ Compared to $\beta 4 \mathrm{~A}$, the most common variant, $\beta 4 \mathrm{~B}$ and $\beta 4 \mathrm{C}$ contain inserts of 53 and 70 amino acids, respectively. Twenty one base pairs are deleted from $\beta 4 \mathrm{D}$. The fifth variant, $\beta 4 \mathrm{E}$, has a markedly 

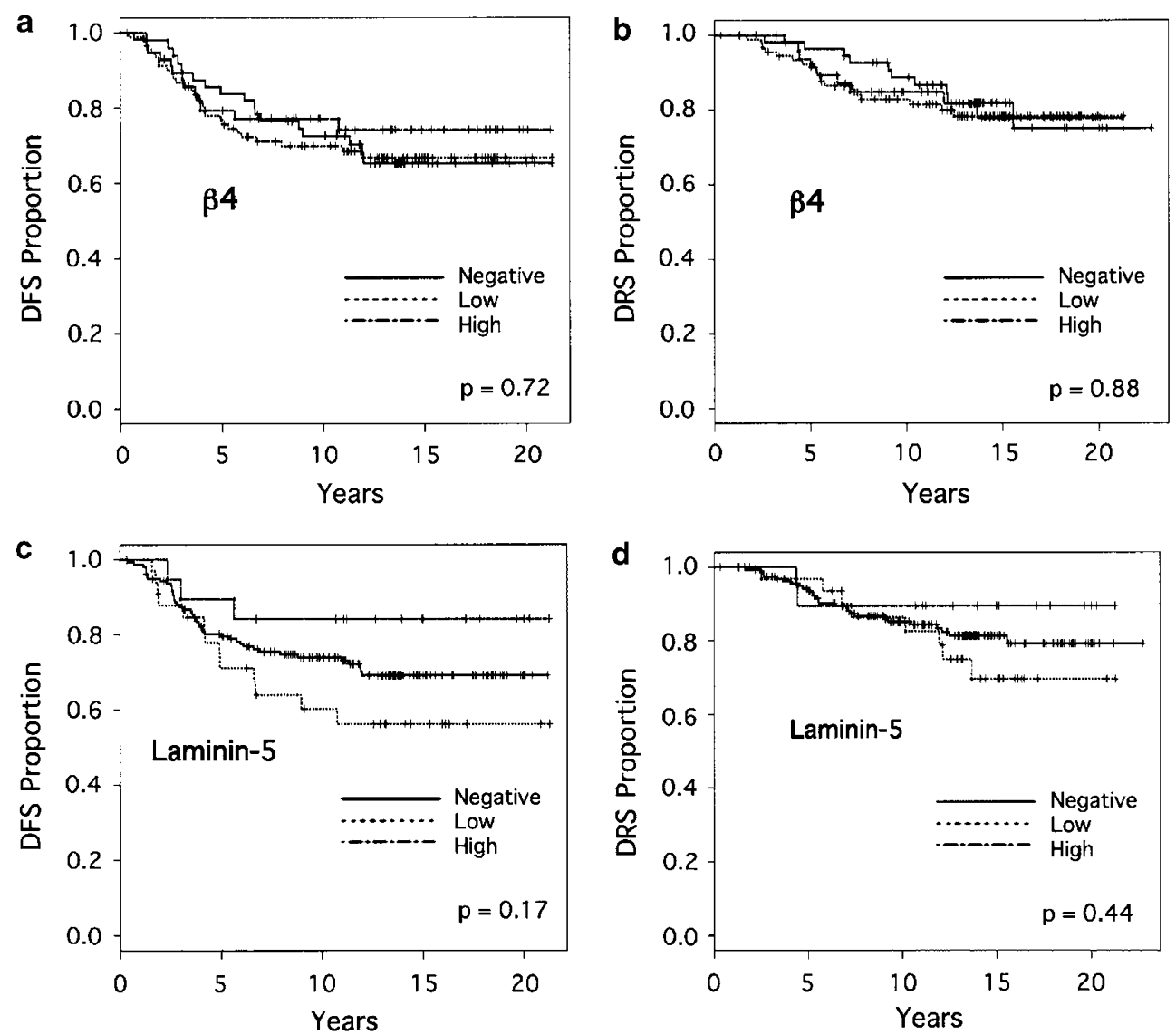

Figure 3 Kaplan-Meier disease-free survival (DFS) curves (a,c) and disease-related survival (DRS) curves (b, d) for patients with nodenegative invasive breast carcinoma in relation to tumor $\beta 4$ mRNA level $(\mathbf{a}, \mathbf{b})$ and peritumoral laminin-5 protein expression level $(\mathbf{c}, \mathbf{d})$.

truncated cytoplasmic domain. Little is known about the functional significance of the $\beta 4$ cytoplasmic variants. A recent report, however, suggests that variants $\beta 4 \mathrm{~B}$ and $\beta 4 \mathrm{C}$ are expressed in very low amounts compared to the predominant $\beta 4 \mathrm{~A} .{ }^{43}$ Some data suggest that these variants, present at a constant ratio in the various tissues and cell lines tested, result from aberrant splicing events that may not have biologic significance. ${ }^{43}$ The $\beta 4$ probe used in this study recognizes each of the variants except $\beta 4 \mathrm{E}$, which would not be expected to function in signaling because of its truncated cytoplasmic domain. ${ }^{14}$

Our study confirms that a group of invasive breast carcinomas exists that overexpresses an integrin characteristic of myoepithelial cells, and that the group with high levels of this integrin represents approximately $25 \%$ of lymph node-negative invasive breast carcinomas. Although cDNA microarray analyses suggest that there is little overlap between the basal/myoepithelial group and the ER-positive and HER-2/neu-positive subsets, we did not observe either a positive or negative correlation between $\beta 4$ expression and ER positivity or HER-2/neu overexpression. We also found no clear association between expression of $\beta 4$ mRNA and laminin-5 protein. Although we cannot rule out the possibility that low levels of laminin-5 below the threshold for detection by immunohistochemical staining might still function in ligand-mediated signaling in invasive breast carcinoma, the deposition of laminin-5-rich basement membranes at the leading edge of invasive tumors, as has been reported for colonic adenocarcinomas, ${ }^{23}$ does not appear to occur in most of the invasive breast carcinomas we examined.

We found no correlation between $\alpha 6 \beta 4$ overexpression and disease-free or disease-specific survival in this patient cohort. These findings do not support a previous study by Tagliabue et $a l^{22}$ reporting a positive correlation between $\alpha 6 \beta 4$ expression in invasive breast carcinoma and decreased survival. Findings from the previous smaller study are surprising considering the small number of patients in the study ( 80 patients) and the low number of events (seven deaths). In that study, $\alpha 6 \beta 4$ protein expression was evaluated by immunohistochemistry using frozen tissue specimens. As a result of the difficulty in accurately detecting $\alpha 6 \beta 4$ protein expression in archival paraffin-embedded tissues, we examined $\beta 4$ mRNA expression by in situ hybridization. We previously reported good sensitivity for detecting $\beta 4$ mRNA with the probe used in our study, ${ }^{24}$ and the proportion of cases with high $\beta 4$ 

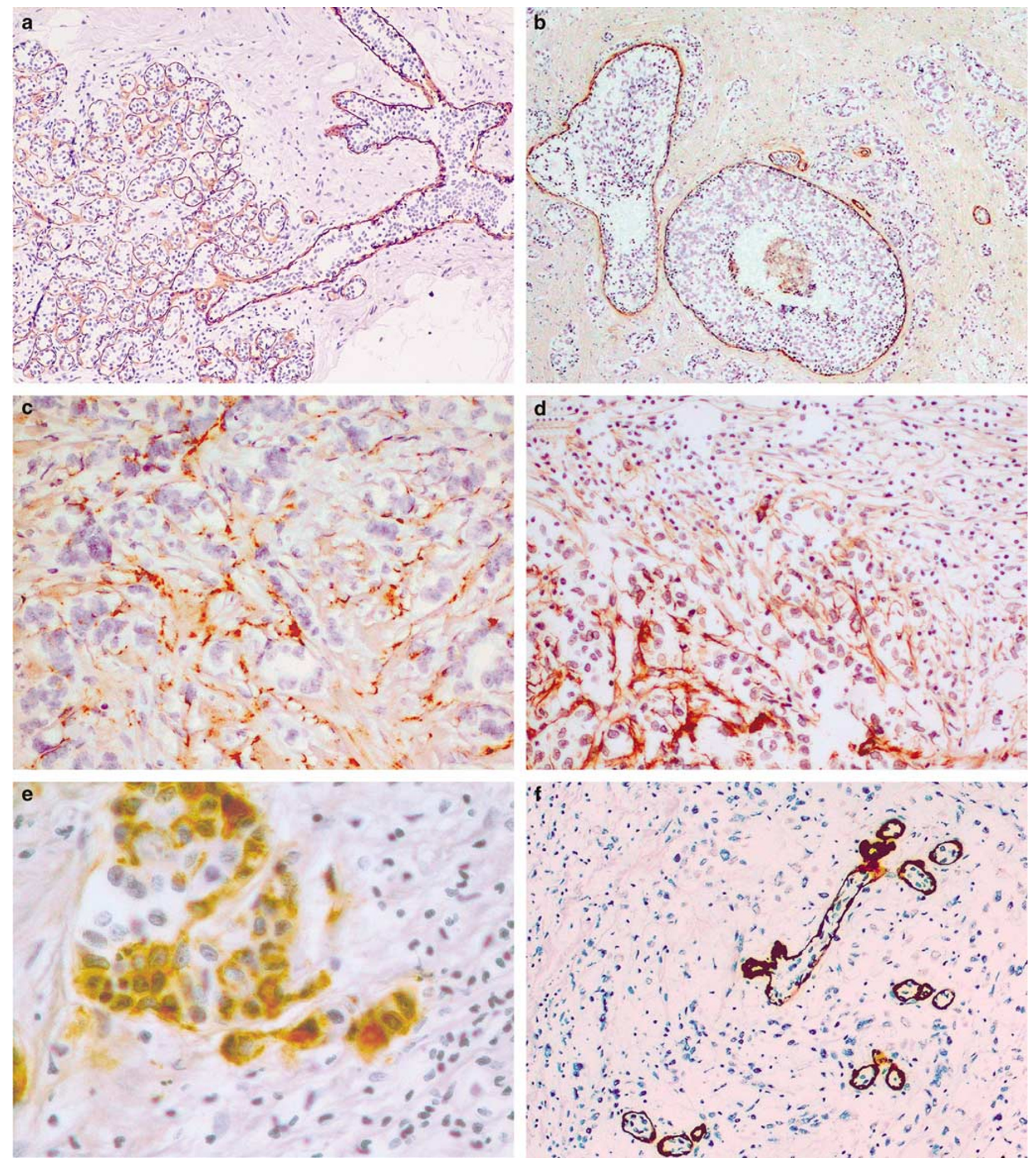

Figure 4 Laminin-5 expression in normal breast tissue, ductal carcinoma in situ (DCIS), and invasive breast carcinoma (immunohistochemical staining with DAB chromogen): (a) normal terminal duct-lobular unit with periductal and perilobular laminin-5 staining (magnification $\times 100$ ); (b) DCIS with periductal laminin-5 staining and adjacent invasive carcinoma without detectable associated laminin-5 (magnification $\times 100)$; (c, d) invasive breast carcinoma with laminin-5 deposited immediately adjacent to invasive tumor cells (magnification $\times 200$ ); (e) invasive breast carcinoma with cytoplasmic expression of laminin-5 (magnification $\times 200$ ); (f) invasive breast carcinoma without detectable associated laminin-5 (tumor cells are infiltrating a normal terminal duct-lobular unit, magnification $\times 200$ ).

mRNA expresssion in our study $(25 \%)$ is within the range of $15-37 \%$ reported for basal/myoepithelial tumors by cDNA microarray analyses. ${ }^{1-5}$ Therefore, we believe that $\beta 4$ mRNA detection in our study is reasonably accurate. Some cases with high $\beta 4$ mRNA expression may not express cell-surface 
Table 4 Correlation between $\beta 4$ integrin and laminin-5 expression

Negative $\beta 4$

Low or high $\beta 4$

Negative $\beta 4$

Low or high $\beta 4$

Negative or low $\beta 4$ High $\beta 4$

Negative or low $\beta 4$ High $\beta 4$
Negative laminin-5

44

103

Negative or low laminin-5

49

127

Negative laminin-5

107

40

Negative or low laminin-5 130 46
Low or high laminin-5

$11(20 \%)$

$P=0.39$

High laminin-5

$6(11 \%)$

$12(8.6 \%)$

$P=0.56$

Low or high laminin-5

$37(26 \%)$

$10(20 \%)$

$P=0.42$

High laminin-5

$14(10 \%)$

$4(8.7 \%)$ a

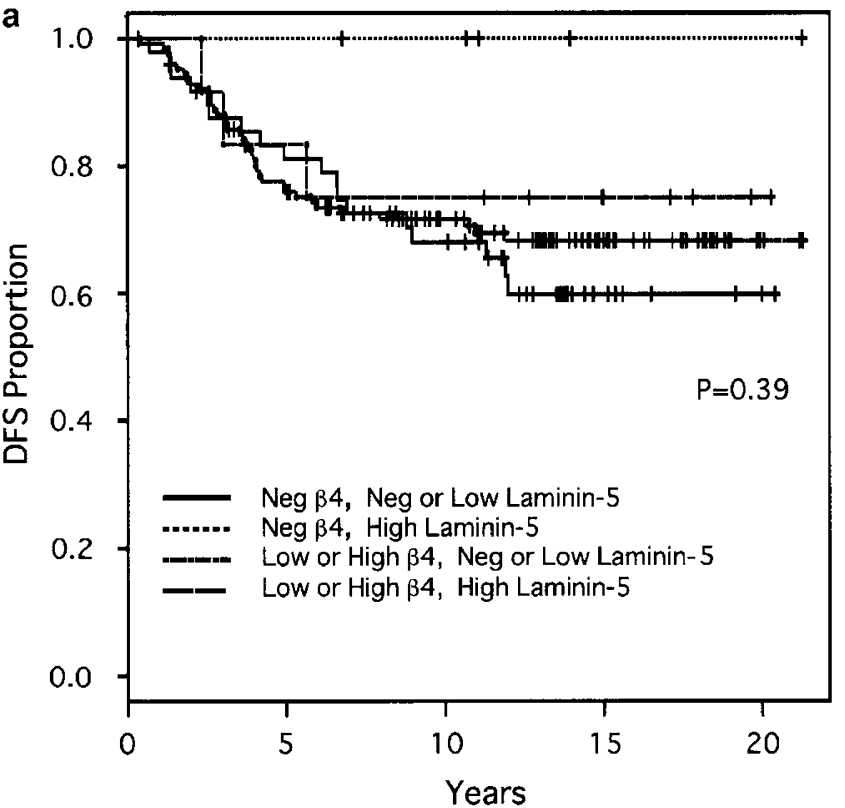

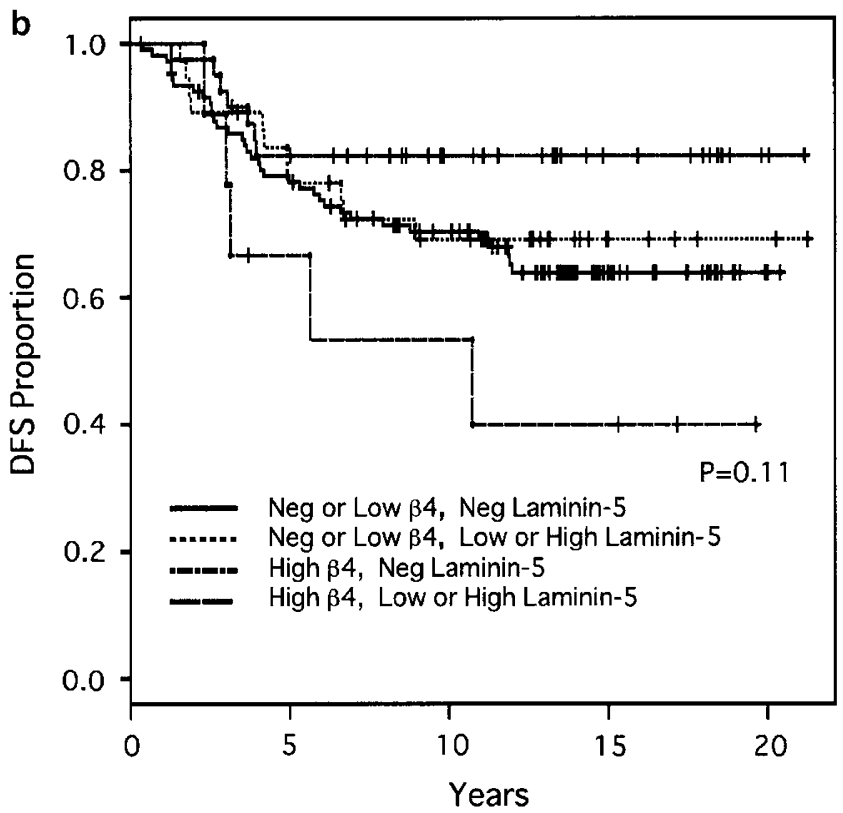

Figure 5 Kaplan-Meier disease-free survival (DFS) curves for patients with node-negative invasive breast carcinoma in relation to combined tumor $\beta 4$ mRNA level and peritumoral laminin-5 protein expression level.

protein, however, and this could account for some differences between the two studies.

Perhaps more importantly, the study by Tagliabue et $a l^{22}$ included many lymph node-positive patients. The prognostic significance of $\alpha 6 \beta 4$ expression may be different in high-stage patients, as has been reported for HER-2/neu overexpression. ${ }^{44,45}$ We did observe a slight trend towards decreased DFS for patients whose tumors had high $\beta 4$ gene expression and coexpression of laminin-5, and this would support the previous findings by Tabliabue et al, but our results did not reach statistical significance $(P=0.11)$. It is possible that a larger clinical study could confirm the adverse prognostic significance of $\alpha 6 \beta 4$ integrin and laminin-5 coexpression in early invasive breast carcinoma, so the prognostic sig- nificance of $\alpha 6 \beta 4$ and laminin-5 coexpression should not be discounted based on our results alone.

Regardless of whether the $\alpha 6 \beta 4$ integrin has prognostic significance, the increased expression of $\beta 4$ mRNA we observed in larger tumors and in higher grade tumors does support the hypothesis that $\alpha 6 \beta 4$ may play a role in tumor progression, as suggested by recent in vitro studies. ${ }^{15-21,28,30,31}$ The $\alpha 6 \beta 4$ integrin identifies a subset of patients with a basal/myoepithelial phenotype for which targeted therapies have not been identified. As opposed to most other markers of the basal/myoepithelial group, the $\alpha 6 \beta 4$ integrin is a cell surface receptor that mediates signal transduction, so it may be an ideal therapeutic target for breast cancer. If therapies are devised which target $\alpha 6 \beta 4$ signaling pathways, 
detection of the $\alpha 6 \beta 4$ integrin could be an important test to identify those patients who might respond to such targeted therapies in the future.

\section{Acknowledgements}

This work was supported by US Army Grant DAMD17-01-1-0298 (MZG) and Cancer Center Support Grant NCI \#CA16672.

\section{References}

1 Perou CM, Sorlie T, Eisen MB, et al. Molecular portraits of human breast tumours. Nature 2000;406: 747-752.

2 Sorlie T, Perou CM, Tibshirani R, et al. Gene expression patterns of breast carcinomas distinguish tumor subclasses with clinical implications. Proc Natl Acad Sci USA 2001;98:10869-10874.

3 Sorlie T, Tibshirani R, Parker J, et al. Repeated observation of breast tumor subtypes in independent gene expression data sets. Proc Natl Acad Sci USA 2003;100:8418-8423.

4 West M, Blanchette C, Dressman H, et al. Predicting the clinical status of human breast cancer by using gene expression profiles. Proc Natl Acad Sci USA 2001;98:11462-11467.

5 van't Veer LJ, Dai H, van de Vijver MJ, et al. Gene expression profiling predicts clinical outcome of breast cancer. Nature 2002;415:530-536.

6 Hynes RO. Integrins: bidirectional, allosteric signaling machines. Cell 2002;110:673-687.

7 Hughes PE, Pfaff M. Integrin affinity modulation. Trends Cell Biol 1998;8:359-364.

8 Clarke AS, Lotz MM, Mercurio AM. A novel structural variant of the human beta 4 integrin cDNA. Cell Adhes Commun 1994;2:1-6.

9 Hogervorst F, Kuikman I, von dem Borne AE, et al. Cloning and sequence analysis of beta- 4 cDNA: an integrin subunit that contains a unique $118 \mathrm{kd}$ cytoplasmic domain. EMBO J 1990;9:765-770.

10 Suzuki S, Naitoh Y. Amino acid sequence of a novel integrin beta 4 subunit and primary expression of the mRNA in epithelial cells. EMBO J 1990;9:757-763.

11 Tamura RN, Rozzo C, Starr L, et al. Epithelial integrin alpha 6 beta 4: complete primary structure of alpha 6 and variant forms of beta 4. J Cell Biol 1990;111: 1593-1604.

12 Iacovacci S, Gagnoux-Palacios L, Zambruno G, et al. Genomic organization of the human integrin beta4 gene. Mamm Genome 1997;8:448-450.

13 Pulkkinen L, Kurtz K, Xu Y, et al. Genomic organization of the integrin beta 4 gene (ITGB4): a homozygous splice-site mutation in a patient with junctional epidermolysis bullosa associated with pyloric atresia. Lab Invest 1997;76:823-833.

14 van Leusden MR, Kuikman I, Sonnenberg A. The unique cytoplasmic domain of the human integrin variant beta4E is produced by partial retention of intronic sequences. Biochem Biophys Res Commun 1997;235:826-830.

15 Shaw LM. Identification of insulin receptor substrate 1 (IRS-1) and IRS-2 as signaling intermediates in the alpha6beta4 integrin-dependent activation of phosphoinositide 3-OH kinase and promotion of invasion. Mol Cell Biol 2001;21:5082-5093.

16 Shaw LM, Rabinovitz I, Wang $\mathrm{HH}$, et al. Activation of phosphoinositide $3-\mathrm{OH}$ kinase by the alpha6beta4 integrin promotes carcinoma invasion. Cell 1997;91: 949-960.

17 Rabinovitz I, Mercurio AM. The integrin alpha6beta4 functions in carcinoma cell migration on laminin-1 by mediating the formation and stabilization of actincontaining motility structures. J Cell Biol 1997;139: 1873-1884.

18 Rabinovitz I, Toker A, Mercurio AM. Protein kinase C-dependent mobilization of the alpha6beta 4 integrin from hemidesmosomes and its association with actinrich cell protrusions drive the chemotactic migration of carcinoma cells. J Cell Biol 1999;146:1147-1160.

19 Rabinovitz I, Gipson IK, Mercurio AM. Traction forces mediated by alpha6beta4 integrin: implications for basement membrane organization and tumor invasion. Mol Biol Cell 2001;12:4030-4043.

20 Chung J, Bachelder RE, Lipscomb EA, et al. Integrin (alpha 6 beta 4) regulation of eIF-4E activity and VEGF translation: a survival mechanism for carcinoma cells. J Cell Biol 2002;158:165-174.

21 O’Connor KL, Nguyen BK, Mercurio AM. RhoA function in lamellae formation and migration is regulated by the alpha6beta4 integrin and cAMP metabolism. J Cell Biol 2000;148:253-258.

22 Tagliabue E, Ghirelli C, Squicciarini P, et al. Prognostic value of alpha 6 beta 4 integrin expression in breast carcinomas is affected by laminin production from tumor cells. Clin Cancer Res 1998;4:407-410.

23 Davis TL, Cress AE, Dalkin BL, et al. Unique expression pattern of the alpha6beta4 integrin and laminin-5 in human prostate carcinoma. Prostate 2001;46: 240-248.

24 Diaz LK, Zhou X, Welch K, et al. Chromogenic in situ hybridization for alpha6beta4 integrin in breast cancer: correlation with protein expression. J Mol Diagn 2004;6:10-15.

25 Leary JJ, Brigati DJ, Ward DC. Rapid and sensitive colorimetric method for visualizing biotin-labeled DNA probes hybridized to DNA or RNA immobilized on nitrocellulose: bio-blots. Proc Natl Acad Sci USA 1983;80:4045-4049.

26 Radinsky R, Bucana CD, Ellis LM, et al. A rapid colorimetric in situ messenger RNA hybridization technique for analysis of epidermal growth factor receptor in paraffin-embedded surgical specimens of human colon carcinomas. Cancer Res 1993;53: 937-943.

27 Ridley AJ, Schwartz MA, Burridge K, et al. Cell migration: integrating signals from front to back. Science 2003;302:1704-1709.

28 Gambaletta D, Marchetti A, Benedetti L, et al. Cooperative signaling between alpha(6)beta(4) integrin and ErbB-2 receptor is required to promote phosphatidylinositol 3-kinase-dependent invasion. J Biol Chem 2000;275:10604-10610.

29 Mainiero F, Pepe A, Yeon M, et al. The intracellular functions of alpha6beta4 integrin are regulated by EGF. J Cell Biol 1996;134:241-253.

30 Mukhopadhyay R, Theriault RL, Price JE. Increased levels of alpha6 integrins are associated with the metastatic phenotype of human breast cancer cells. Clin Exp Metastasis 1999;17:325-332. 
31 O’Connor KL, Shaw LM, Mercurio AM. Release of cAMP gating by the alpha6beta4 integrin stimulates lamellae formation and the chemotactic migration of invasive carcinoma cells. J Cell Biol 1998;143: 1749-1760.

32 Mainiero F, Murgia C, Wary KK, et al. The coupling of alpha6beta4 integrin to Ras-MAP kinase pathways mediated by Shc controls keratinocyte proliferation. EMBO J 1997;16:2365-2375.

33 Klemke RL, Cai S, Giannini AL, et al. Regulation of cell motility by mitogen-activated protein kinase. J Cell Biol 1997;137:481-492.

34 Nagato T, Yoshida H, Yoshida A, et al. A scanning electron microscope study of myoepithelial cells in exocrine glands. Cell Tissue Res 1980;209:1-10.

35 Tavassoli FA. Myoepithelial lesions of the breast. Myoepitheliosis, adenomyoepithelioma, and myoepithelial carcinoma. Am J Surg Pathol 1991;15: 554-568.

36 Schnitt SJ, Silen W, Sadowsky NL, et al. Ductal carcinoma in situ (intraductal carcinoma) of the breast. N Engl J Med 1988;318:898-903.

37 Silverberg SG, Chitale AR. Assessment of significance of proportions of intraductal and infiltrating tumor growth in ductal carcinoma of the breast. Cancer 1973;32:830-837.

38 Martin KJ, Kwan CP, Nagasaki K, et al. Downregulation of laminin-5 in breast carcinoma cells. Mol Med 1998;4:602-613.
39 de Melker AA, Sonnenberg A. Integrins: alternative splicing as a mechanism to regulate ligand binding and integrin signaling events. Bioessays 1999;21: 499-509.

40 Hogervorst F, Kuikman I, van Kessel AG, et al. Molecular cloning of the human alpha 6 integrin subunit. Alternative splicing of alpha 6 mRNA and chromosomal localization of the alpha 6 and beta 4 genes. Eur J Biochem 1991;199:425-433.

41 Delwel GO, Kuikman I, Sonnenberg A. An alternatively spliced exon in the extracellular domain of the human alpha 6 integrin subunit-functional analysis of the alpha 6 integrin variants. Cell Adhes Commun 1995;3:143-161.

42 Tamura RN, Cooper HM, Collo G, et al. Cell typespecific integrin variants with alternative alpha chain cytoplasmic domains. Proc Natl Acad Sci USA 1991;88:10183-10187.

43 Micheloni A, Falcioni R, Zambruno G, et al. The human integrin beta4B and beta4C variants are not expressed in a tissue-specific manner. FEBS Lett 2002; 519:238-239.

44 Tandon AK, Clark GM, Chamness GC, et al. HER-2/neu oncogene protein and prognosis in breast cancer. J Clin Oncol 1989;7:1120-1128.

45 Gusterson BA, Gelber RD, Goldhirsch A, et al. Prognostic importance of c-erbB-2 expression in breast cancer. International (Ludwig) Breast Cancer Study Group. J Clin Oncol 1992;10:1049-1056. 